\title{
REPORT ON POPLAR HYBRIDIZATION II 1937 AND 1938
}

\author{
By C. Heimburger \\ Dominion Forest Service
}

\begin{abstract}
The results of further progress in a poplar hybridization project initiated in 1935 with the aim of producing valuable hardy and disease resistant material of rapid growth for the production of wood of high quality for industrial purposes, and of value for shelterbelts in the Prairies are reported. It has been possible to cross the native aspens of Eastern and Western Canada with several exotic aspens and their of Eastern and Western Canada with several exotic aspens and their hybrids with silver poplar, and to obtain hybrid material of great promise for these purposes. Some western balsam poplars have also been shelterbelts. An attempt to cross an aspen with a cottonwood has so far yielded indifferent results. The cross of a basket willow with a cottonwood was not successful. Hardiness, disease resistance, and good propagability from stem; or root cuttings are at present the most important characters used in evaluating the young hybrids.
\end{abstract}

$\mathrm{T}$

HE OBJECT of this report is to outline the further development of the poplar hybridization project initiated in 1935 and described previousiy (Heimburger, 1936). It is an attempt to produce new varieties of aspen poplars, suitable for reforestation on upland soils and yielding good, sound wood for the manufacture of match stock, veneer, and pulp. The new varieties should be fully hardy, resistant to several important diseases damaging the native aspen poplars, and should possess superior growth characters as compared with the native asfens. Since hybridization and selection are the methods most commonly employed with such outstanding results in breeding work with other plant material, these methods are here applied to the development of superior aspen poplars. In more recent years the desirability of producing suitable tree varieties for shelterbelts in the Prairies has become increasingly apparent and some of the efforts are therefore directed towards the breeding of aspens and other poplars for these purposes also.

In 1935 and 1936 it was found that the European silver poplar (Populus alba L.) and its natural hybrid with the European aspen ( $P$. tremula L.), the so-called gray poplar (P. canescens $\mathrm{Sm}$.) could be crossed successfully with the native aspens ( $\mathrm{P}$. tremuloides Michx. and P. grandidentata Michx.). The cross between the two native aspens, $\mathrm{P}$. tremuloides $\mathrm{x}$ grandidentata was also successful.

HYBRIDS OF 1936

In the fall of 1936 the hybrid seedlings described in the previous report were carefully dug out and their roots prepared into cuttings, care being taken to keep the cuttings from each seedling separately. Each bunch of root cuttings thus represented a singe clone (Schreiner, 1939). The material was then trans. ferred to the nursery of the Petawawa Forest Experiment Station and planted. The possibility of propagating aspen poplars by means of fall-planted root cuttings had been ascertained in previous tests with root cuttings of native aspens. Fall planting of root cuttings of aspen poplars as compared with spring planting has the advantage of affording better seasonal distribution of nursery work; the cuttings are then fully dormant which has been found essential to their proper establishment; the snow cover at the Petawawa Forest Experi- 
ment Station is as a rule of sufficient depth and duration to afford the planted cuttings ample protection during the winter; the survival of material planted in this way is believed to be a good test of its general adaptation to the local climate. In other regions with less abundant and persisting snow cover, spring planting of root cuttings of aspens will probably have to be employed, thus necessitating a storage of the material under artificial protection during the winter, in order to keep it dormant in the spring. Root cuttings of some European aspens do not survive the winters when planted in the fall at the Petawawa Forest Experiment Station and have to be treated in the manner indicated above. This is considered a disadvantage, indicates poor adaptation to the local climate, and is probably one of the causes of the poor propagability of this material.

In the summer of 1937 the hybrids showed some striking differences in survival, depending on their parentage. All the $\mathrm{P}$. tremuloides $\mathrm{x}$ grandidentata as well as the P. alba $\mathrm{x}$ grandidentata clones survived, while some of the $P$. canescens $x$ grandidentata clones perished. The survival of the tremuloides-grandidentata clones was uniformly very good, the alba-grandidentata clones varied somewhat in this respect, the canescens-grandidentata clones showing the greatest variation. This indicates poor adaptation to climate and low ability of establishment by some of the latter. As the canescens-grandidentata clones already have shown great variation in their morphological characters (Heimburger, 1936), probably because one of their parents is a hybrid, a variation in physiological characters influencing propagability was expected. During 1938 and 1939 all the hybrids were propagated by means of root cuttings and grown in the nursery. Some of the clones showing poor survival, poor growth or susceptibility to die-back caused by Napicladium sp. were discarded.

All the tremuloides-grandidentata clones have so far shown very good survival and a fair degree of resistance to rust caused by Melampsora sp. but only medium to poor growth and were severely attacked by die-back. The rather poor growth and susceptibility to die-back of this material makes it unsuitable for any direct use in forestry. Some of it is being retained for possible future use in breeding. It is highly probable that the poor growth and susceptibility to die-back which exceeds that of the parent species, is one of the causes of the extremely rare occurrence of these hybrids in nature. Thus extreme susceptibility of some hybrids to disease may be added to the mechanisms of isolation, maintaining species differences in nature, mentioned by Dobzhansky (1937).

The alba-grandidentata clones have maintained a somewhat varying but nevertheless very marked inherent hybrid vigour in comparison with the growth of their parent species. They have not been attacked to any extent by Melampsora rust and only very slightly by Napicladium die-back. Most of this material can be easily propagated by means of root cuttings and shows great promise of yielding valuable varieties for direct use in forestry. The supposed natural hybrids of P. alba and P. grandidentata found in 1935 (Heimburger, 1936) and later (Peto, 1938) are in their juvenile shoots identical with the artificially produced alba-grandidentata clones and thus their parentage is now certain. 
The canescens-grandidentata clones have continued to show great variation in survival and growth rate; some have been attacked by die-back. About two thirds of the original number of clones have been discarded because of poor survival, poor growth, and susceptibility to die-back. The remaining selected clones represent some of the most promising material at hand to date. In rate of growth, resistance to die-back and to rust, and ease of propagation by root cuttings some of these are slightly superior to the alba-grandidentata clones at hand. The cross $P$. canescens $x$ grandidentata can be regarded as the most successful of the earlier crosses in spite of the great number of inferior seedlings it has yielded. By selecting better $P$. canescens in respect to growth form and repeating this cross on a larger scale it should be possible to utilize the inherent variability of $\mathrm{P}$. canescens to still greater advantage than has been possible so far.

CROSSES OF 1937

The hybridization project was continued in the early spring of 1937 , the same crossing technique being employed as in previous years. Through the courtesy of Dr. H. T. Güssow, space and other facilities were made available in the greenhouses at the Central Experimental Farm in Ottawa. Twigs of female $\mathrm{P}$. alba and $\mathrm{P}$. canescens were again obtained from the arboretum of the Central Experimental Farm. Twigs of female P. grandidentata were obtained from marked trees at the Petawawa Forest Experiment Station. Twigs of male P. alba L. var. Bolleana Lauche were obtianed from Buchart's Gardens near Victoria, B.C. through the courtesy of Mr. A. E. Pickford of the British Columbia Forest Branch. This is a variety of silver poplar with an upright pyramidal growth habit of which no twigs with flower buds could be obtained at that time in Eastern Canada. The growth form of most of the P. alba introduced into Canada and available for hybridization is very poor and is undoubtedly inherited by some of their hybrid offspring as evidenced by the growth form of some natural hybrids. It was therefore found desirable to use a more straight-growing form of $\mathrm{P}$. alba in crosses with aspens.

Through the courtesy of Dr. E. H. Moss of the University of Alberta, twigs from a good male P. tremuloides growing near Edmonton, Alberta, were obtained. It was found desirable to use the western, more drought-resistant form of the native aspen in some preliminary crosses, in view of the possibilities of producing new and valuable drought-resistant hybrid poplars for shelterbelts in the Prairies. The need of hardy and drought-resistant material for shelterbelts in the Prairies is recently becoming more and more urgent and the aspen native to the Prairies may have possibilities in this respect. It is fully hardy and more drought-resistant than other native and introduced poplars in the northern part of the Prairies (Moss, 1932), although it is rather slow-growing. The feasibility of long-distance shipment of dormant twigs with flower buds of male poplars for use in crossing according to the method of Wettstein (1933 a) was established in 1936. P. alba and its hybrids with aspen are known to possess a high degree of drought-resistance (Bogdanov, 1936, Wettstein, 1937 a) and are used to some extent in shelterbelts in southeastern Russia (Bogdanov, 1936) and South Africa (Hubbard, 1936), in regions with hot, dry summers. The cross of drought-resistant aspens native to the Prairies with this material can be expected to yield 
valuable hybrids combining the drought-resistance of both parent species with the winter-hardiness of the native aspen.

The crosses $\mathrm{P}$. canescens $\mathrm{x}$ alba var. Bolleana and $\mathrm{P}$. grandidentata $\mathrm{x}$ alba var. Bolleana were made in February. The first cross yielded many good seeds while the second cross was unsuccessful. Although the female catkins of P. grandidentata at first showed the characteristic rapid elongation following fertilization described by Albensky and Delitsina (1934), they all dropped off the twigs before the seeds matured. Several unsuccessful attempts were made during the same year to bring female P. grandidentata catkins to maturity in the greenhouse. Wettstein (1933 a) states that different poplar species in his crosses have shown marked differences in the capacity of their twigs to develop mature seeds under greenhouse conditions. Later (Wettstein, $1937 \mathrm{~b}$ ), individual differences within the same species in the capacity of bringing catkins to maturity and yielding good seeds under greenhouse conditions are reported. In successfully effecting the cross $P$. grandidentata $x$ tremula, Wettstein (1938) has shown that it is possible to use P. grandidentata as a female parent in greenhouse crosses. The twigs of the female P. grandidentata used in the crosses in Ottawa were collected from a rather old tree; they were slow-growing and had most of the flower buds situated on short shoots. Twigs from younger trees with the buds growing on long and strong shoots would probably give better results. In March, the cross P. canescens $\mathrm{x}$ tremuloides (western) was made and yielded many good seeds. In this cross the same female $P$. canescens was used as in the two previous years, and it must be noted that twigs of this tree have consistently been very good seed bearers, even under rather adverse conditions in the greenhouse. This is probably a case of individual variation in seed-bearing capacity. Later, in April, the cross $\mathrm{P}$. alba $\mathrm{x}$ tremuloides (western) was made. This cross was not successful, chiefly because the spring being too advanced, it was too hot in the greenhouse and the growing catkins began to fall off the twigs. Early catkins elongation showed, however, that this cross in all probability was feasible and that fertilization had taken place.

The seeds of the two successful crosses were cleaned and again given to Mr. Rawley Frith of Ottawa, who kindly agreed to raise the hybrid seedlings, as in the previous year. Instead of sterilizing the soil with formaldehyde to prevent damping off it was treated with a commercial disinfectant "cupricide." The seeds germinated very well, especially those of the cross $P$. canescens $x$ tremuloides (western), of which several hundred seedlings were at hand. The effect of the "cupricide" however, proved disastrous a short time after germination, and nearly all the seedlings were lost, probably through poisoning by the disinfectant. Only a few plants of the cross $P$. canescens $x$ alba var, Bolleana survived the treatment and were planted out in the garden. In the fall of 1937 only two good plants of the latter cross were selected for further propagation and testing, the remaining few plants being dwarf or extremely branchy types. The two selected plants were transferred to the nursery of the Petawawa Forest Experiment Station and propagated by means of root cuttings. Both seedlings were quite branchy, the buds in the leaf axils of the lower part of the stem forming vigorous side-branches during the same summer. One of the seedlings had the fastigiate branching habit of P. alba var. 
Bolleana, combining it with leaf and stem characters resembling those of $\mathrm{P}$. canescens. The other seedling had normal, divergent branching and leaf and stem characters of $P$. alba. The leaves of this seedling are more deeply lobate than leaves of young shoots of the typical $\mathrm{P}$. alba and in this respect resemble those of its male parent. Although two seedlings are by far not sufficient for a determination of the inheritance of certain branching and leaf characters, they show that type of branching and leaf characters can be inherited independently. As the female parent, $P$. canescens, is a hybrid, it is as yet not possible to state whether the excessive juvenile branchiness of both of the seedlings and the fastigiate habit of one of these are inherited from their male parent. P. alba var. Bolleana has only relatively recently been introduced from Turkestan (Rehder, 1927) and it must be assumed that the P. canescens used in this cross is a hybrid of a typical normally branched P. alba with an aspen having the usual type of branching. This cross therefore indicates that the fastigiate habit of P. alba var Bolleana is, at least in part, dominant and transmitted to some of its offspring. Since excessive juvenile branchiness has been found in much other $\mathrm{P}$. alba and $\mathrm{P}$. canescens material, it is not as yet possible to determine whether the branchiness of the two seedlings in ques. tion has been inherited from their male or from their female parent, or from both. It must be mentioned, however, that no hybrid seedlings of the previous year having the same $P$. canescens as their female parents, ever showed excessive juvenile branchiness. This character is undesirable in the production of clear wood for match stock, veneer, and pulp and it would therefore be of interest to study its mode of inheritance in further crosses.

CRosses of 1938

The poplar hybridization project was continued in the spring of 1938, in co-operation with the Division of Biology and Agriculture of the National Research Council under the Associate Committee on Plant Hormones, which was formed late in 1937. Greenhouse space and other facilities were kindly made available by the Division of Biology and Agriculture at the National Research Laboratories and it was possible to continue the work on a much larger scale. Twigs of male and female P. tremuloides Michx. (western) were again obtained, this time from the vicinity of Calgary, Alberta, through the courtesy of Mr. H. L. Holman, of the Dominion Forest Service. Mr. W. R. Reader, Park Superintendent of the City of Calgary, kindly forwarded twigs with flower buds of female P. acuminata Rydb. and of "Northwest Poplar" which is a male clone. This material was obtained for the purpose of continuing the efforts of 1937 in the production of superior poplars for shelterbelts in the Prairies. The P. tremuloides (western) material was collected from two poplar bluffs on a very exposed and dry situation, and should therefore be quite hardy and drought-resistant. The P. tremuloides from Calgary probably belongs to the variety P. t. var. aurea Tidest. (Tidestrom, 1911) as shown by the characters of the catkins, the flower bracts, and the flowers. In contrast to this the $\mathrm{P}$. tremuloides received previously from Edmonton did not differ appreciably in its flower characters from the P. tremuloides of Eastern Canada. Additional flower material kindly forwarded by Dr. E. H. Moss from Edmonton in the summer of 1938 was typical P. tremuloides. 
P. acuminata Rydb. is not native to the region around Calgary, Alberta, but is found in southern Alberta. According to information received from Mr. W. R. Reader, it is quite drought-resistant and is not damaged by chinooks to the same extent as are the other poplars planted in and around Calgary. "Northwest Poplar" is said to originate from North Dakota and recently is being planted extensively in the Prairie Provinces because of its healthy growth and hardiness. In its morphological characters it is quite similar to P. Jackii Sarg. which is considered a natural hybrid between the cottonwood (P. deltoides Marsh) and the balsam poplar (P. tacamahacca Mill.) and is found wherever the natural ranges of these two species overlap. In all probability the Northwest poplar is a natural hybrid between the cottonwood ( $\mathrm{P}$. deltoides Marsh.) and the balsam poplar of the Prairies ( $\mathrm{P}$. tacamahacca Mill. var. Michauxii Farwell) exhibiting hybrid vigour and there. fore taken into cultivation.

Through the courtesy of Mr. W. H. Judd, propagator of the Arnold Arboretum, twigs of male Chinese aspen ( $\mathrm{P}$. adenopoda Maxim.) were obtained from a specimen growing in the arboretum. This species is said to occur in central and western China (Rehder, 1927) and could therefore possibly contribute additional hardiness and drought resistance to its hybrids with other aspen poplars.

Twigs of female P. tremuloides and of male and female P. grandidentata were again obtained from marked trees at the Petawawa Forest Experiment Station. Twigs of a female $\mathrm{P}$. alba $\mathrm{x}$ grandidentata natural hybrid (AG32) and of male triploid P. canescens (C5) and P. alba (A1) examined cytologically by Dr. F. H. Peto (Peto, 1938) were collected in the vicinity of Ottawa. Twigs of female P. canescens and P. alba as well as of male triploid P. alba (A2-Peto, 1938) were obtained from the arboretum of the Central Experimental Farm. In addition, twigs of female P. berolinensis Dippel and of male P. Eugenei Simon Louis were obtained at the Central Experimental Farm. P. berolinensis is a hybrid of P. laurifolia Ledeb. and Lombardy poplar (Cansdale et al., 1938). It belongs to the group of so-called Russian poplars planted widely in the Prairies. P. Eugenei is believed to be a hybrid of P. regenerata and Lombardy poplar (Cansdale et al., 1938) P. regenerata is one of the many hybrids between the American cottonwood and the European black poplar originated in western Europe.

With this material several crosses yielded good seeds. The seeds were harvested and the seedlings were grown in the greenhouses of the National Research Laboratories by Dr. L. P. V. Johnson who was appointed forest geneticist by the National Research Council at that time. Soil sterilization with formaldehyde to prevent damping-off was again used with good results. The young seedlings were later transplanted to the nursery of the Petawawa Forest Experiment Station for testing and propagation. Of the numerous crosses made, the following have yielded hybrid seedlings:

$P$. canescens $x$ tremuloides var. aurea. This cross was made on a rather large scale and yielded several thousand seedlings. Many seedlings were lost in the initial transplanting from the flats to the nursery and some were later discarded because of unsatisfactory growth. At the present time about 1500 seedlings of this cross are at hand. In contrast to the P. canescens $\mathrm{x}$ 


\section{POPLAR HYBRIDIZATION-HEIMBURGER}

grandidentata hybrids, this material is rather uniform in its vegetative char. acters, those of the male parent predominating. The plants are rather slow. growing as compared with other hybrid poplars, but ripen their shoots and loose their leaves very early in the fall. During 1938 and 1939 this material was heavily infected with Melampsora rust and suffered some set-back in growth because of this. A few plants were less heavily infected by rust and are apparently more rust-resistant. Since P. canescens and its other hybrids show but very light infection by Melampsora rust and grow much faster, it must be presumed that susceptibility to the form of Melampsora rust found at Petawawa and the slow growth are inherited from the western trembling aspen. This is not necessarily a disadvantage because the material is intended for use in the Prairies where it may not be susceptible to the local forms of Melampsora rust, and where rapid growth is less essential than hardiness and drought-resistance. Seedlings of $P$. tremuloides raised from seed kindly sup. plied by Dr. E. H. Moss from Edmonton, show similar heavy infection by Melampsora rust, slow growth, and early leaf-fall. Cuttings of balsam poplars from Calgary have also yielded rather slow-growing and heavily rusted plants at Petawawa, and yet this material is known to be reasonably free from rust and drought-resistant in the Prairies. It is possible that the form of Melampsora rust found at Petawawa differs in several respects from the form found in the Prairies and therefore causes heavy infections on western poplar material grown at Petawawa. It is also possible that the western poplars are heavily infected by rust in the East because they are growing in an environment to which they are not fully adapted. Further tests with this material in the Prairies are necessary to establish its adaptation to climate and usefulness in shelterbelts.

P. (alba $x$ grandidentata) $x$ tremuloides var. aurea. This cross also represents a back-cross of an $P$. alba-aspen hybrid with an aspen and has yielded some sixty plants after a rather heavy mortality in the transplanting of the seedlings and elimination of dwarfs. The hybrid seedlings resemble those of the previous cross in their fairly uniform similarity to the male parent and their rather slow growth. The material has also been rather heavily infected by Melampsora rust at Petawawa. By their slightly larger leaves some of the seedlings show the influence of the P. grandidentata parentage. This cross is another instance of the predominance of the vegetative characters of the western aspen.

$P$. (alba $x$ grandidentata) $x$ canescens triploid yielded only a few seeds which resulted in one hybrid plant. This plant has so far been reasonably fast growing and free from disease. Nothing is as yet known about its cytology. This cross indicates the possibility of using the triploid $P$. canescens found planted around Ottawa as a male parent and thus of producing valuable new forms which may be polyploids, in the same way as the male triploid aspen discovered recently in Sweden (Nilsson-Ehle, 1936, Müntzing, 1936) has been used in the production of new polyploid forms (Nilsson-Ehle, 1938).

P. (alba $x$ grandidentata) $x$ Eugenei is a cross between an aspen hybrid and a cottonwood hybrid. Wettstein (1933 a) has successfully used P. alba which is closely related to the aspens, as female parent in crosses with several 
poplars of the cottonwood group, and the resulting hybrids are said to be quite vigorous. Stout and Schreiner (1933 and 1934) have successfully crossed the native cottonwood with P. grandidentata as the male parent, and have obtained seedlings of rather slow growth and showing the predominance of aspen characters, including poor rooting capacity from stem cuttings. Recent tests at the Petawawa Forest Experiment Station have shown that native cottonwoods exhibit great individual variation in the rooting capacity from stem cuttings, some clones rooting very poorly. The rooting capacity from stem cuttings of the cottonwood used as parent in the cross by Stout and Schreiner is as yet unknown. Since none of the $\mathrm{P}$. alba $\mathrm{x}$ grandidentata material tested so far roots well from stem cuttings, although it is far superior in this respect to the native aspens, it was found desirable to cross it with $\mathrm{P}$. Eugenei which is known to root very readily from cuttings. The cross was not very successful; it yielded few seeds and the resulting plants are not exceptionally vigorous. They have inherited some of the pubescence and other aspen characters from their female parent and, unfortunately, most of the susceptibility to Melampsora rust from P. Eugenei. Their capacity to root from stem cuttings is being tested. Although this cross is not very promising, it should be possible to combine the valuable characters of aspen poplars with those of the cottonwoods, by a more careful selection of parent material after additional knowledge of character inheritance has been obtained.

$P$. tremuloides $x$ adenopoda is a cross between the native trembling aspen and Chinese aspen. The twig material of the male parent was scarce and thus the cross was carried out on a small scale. It yielded several very promising seedlings, uniformly intermediate in their vegetative characters between their parent species. They show pronounced hybrid vigour but are somewhat susceptible to Melampsora rust. Their propagability from root cuttings is being tested. It is possible that this material will be of value in the Prairies where their reaction towards Melampsora rust may be different.

$P$. tremuloides $x$ alba triploid was not very successful. This cross yielded a few seeds which produced several dwarfs and one weak hybrid plant, resembling the male parent rather than the female, and of no practical value. The male parent is a rather slow'growing type and appears far less promising for the production of valuable polyploid forms than the triploid $\mathrm{P}$. canescens mentioned previously.

$P$. acuminata $x$ Eugenei is a cross between a balsam poplar and a cottonwood hybrid. According to Wettstein (1933 b) hybrids of balsam poplars with cottonwoods as a rule are very vigorous. Most of the outstanding poplar selections of Stout and Schreiner (1933) exhibiting marked hybrid vigour are also hybrids of balsam poplars with cottonwoods. The seedlings resulting from this cross are quite vigorous, although there is a great variation in their vegetative characters and susceptibility to Melampsora rust. This is to be expected since their male parent is a hybrid. Although both parents are quite susceptible to Melampsora rust at the Petawawa Forest Experiment Station, some of the seedlings resulting from this cross have so far been free from rust. This indicates the possibility of producing rust-resistant poplars even in crossing susceptible forms if variation in this respect can be induced by using hybrid forms as parents. The seedlings of this cross are rather late 
in maturing their shoots and in their leaf-fall and are thus in all probability suitable for growing in the southern part of the Prairies only. Since P. acuminata is native to southern Alberta and P. Eugenei is a rather latematuring form, this behaviour of the seedlings is to be expected. To what extent the superior drought and chinook resistance of the female parent is inherited by these hybrids can best be ascertained by actual tests in the Prairies. About a dozen plants are now at hand after culling out some dwarfs and crooked forms among the very young seedlings. As the P. acuminata used in this cross roots rather poorly from stem cuttings, the rooting capacity of the hybrids is being tested also.

$P$. berolinensis $x$ Northwest poplar. Both parents in this cross are hybrids of balsam poplars with cottonwoods, i.e. products of rather wide crosses. The seedlings of this cross show very marked variations in growth rate and in their leaf and stem characters, as was to be expected in a cross of two hybrids. Of the 26 plants selected after discarding some dwarf seedlings, 12 show the excessive juvenile branchiness described under P. alba var. Bolleana and characteristic of $\mathrm{P}$. berolinensis, while the remaining 14 have clean stems. This indicates that the excessive juvenile branchiness of the $\mathrm{P}$. berolinensis used in this cross is dominant and may be transmitted to about one-half of the progency. The expression of this character may be caused by one single dominant gene. While excessive juvenile branchiness is regarded as being undesirable for the production of clear wood for industrial purposes, it is a desirable character for shelterbelt material. P. berolinensis and several other so-called Russian poplars are seriously injured by Septoria canker, especially when planted in the Prairies (Bier, 1939, Peace, 1939). According to the inoculation experiments of Bier (1939), Northwest poplar is also very susceptible to Septoria canker, although eastern strains of its supposed parent species were found relatively resistant. It is still unknown whether all $P$. Jackii material found in nature is more susceptible to Septoria canker than its supposed parents and thus behaves as the P. tremuloides $\mathrm{x}$ grandidentata do in respect to die-back. The fact that Saskatchewan poplar, another P. Jackii of the Prairies, is less susceptible to Septoria canker than Northwest poplar (Bier, 1939) indicates individual variation in relative susceptibility to this disease among native poplars and their hybrids. "Therefore, if the progeny of an artificial cross between balsam poplar and cottonwood were carefully selected for hybrid vigour and disease resistance, it is quite possible that a form would be derived that possessed the growth characters of 'Northwest' and Saskatchewan poplar, and the resistance of the parent trees" (Bier, 1939: 204). It is highly probable that such a possibility exists within the material derived from this cross, as the extreme variability in morphological characters usually indicates a similar variability in physiological characters and thus in relative disease resistance. Both $\mathrm{P}$. berolinensis and "Northwest" poplar are severely attacked by Melampsora rust at Petawawa, and their hybrids also show a high degree of susceptibility to rust. As mentioned previously, this does not necessarily mean that all the hybrids will be highly susceptible to Melampsora rust in the Prairies. For the purpose of producing valuable material for shelterbelts in the Prairies this cross appears to be very promising and it is therefore being repeated on a larger scale. The use of other $\mathrm{P}$. 
Jackii material, more resistant to Septoria canker and Melampsora rust than "Northwest" poplar, will probably increase the chances of obtaining canker and rust resistant forms in future crosses of this kind. In respect to drought and chinook resistance, this cross will probably be inferior to material derived from the native aspen of the Prairies or from P. acuminata and related forms, although it will greatly surpass these in rate of growth. However, different regions and soils in the Prairies will most probably require different shelterbelt material and it is not probable that one "universal" poplar for shelterbelts would be the best one to use everywhere.

Besides the crosses mentioned above, several other crosses were attempted in 1938 which were not successful. Crosses in which P. grandidentata from Petawawa was used as'female parent all failed because the catkins dropped before reaching maturity, as was the case during previous years. Female twigs of $\mathrm{P}$. tremuloides var. aurea from Calgary behaved in a very similar manner. They were also collected from rather old, slow-growing trees and failed to develop mature catkins, although showing rapid catkin elongation after crossing with several aspen poplars and their hybrids. A couple of other crosses having P. alba and P. tremuloides as female parents failed because they were performed too late in the season and it became too hot and dry in the greenhouse. February and March seem the best months for poplar hybridization in greenhouses under the present conditions. Crosses made in April have so far failed.

In a paper on the propagation of poplars through grafting Bogdanov (1934) shows that it is only possible to graft poplars successfully according to the series: aspens-silver poplars-cottonwoods-balsam poplars, and thus the grafting of aspen on cottonwood or of silver poplar on balsam poplar gives poor results. This series entirely corresponds to the series of successful crosses set up by Wettstein (1933 b) and is in accord with the results of Stout and Schreiner (1933) strongly indicating a similar series in genetic affinity of the different poplars. Bogdanov also was able to graft $\mathrm{P}$. nigra, a cottonwood, successfully on Salix viminalis, a species of basket willow. Since it would be highly desirable to combine some of the valuable characters found in basket willows with those of the cottonwoods, the cross Salix viminalis $\mathrm{x}$ Populus Eugenei was attempted with material obtained from the arboretum of the Central Experimental Farm. It was quite possible to bring the female willow branches to flower in the greenhouse and then to effect the cross. However, the result was entirely negative. The catkins did not even show elongation after the application of poplar pollen and soon fell off the twigs. Salix viminalis belongs to a group of willows embracing a great number of species and thus offering further possibilities in this direction. The results of wide crosses within the willows obtained by Heribert-Nilsson (1918), especially the crosses of tree willows with shrubby species resulting in dwarf hybrids indicate, however, that a poplar-willow hybrid, if successfully produced, probably would be a dwarf and of no direct use to forestry. It would undoubtedly be of great scientific interest and of value for further breeding projects.

ACKNOWLEDGMENTS

The author is indebted to Dr. H. T. Güssow, Mr. H. L. Holman, Mr. W. H. Judd, Dr. E. H. Moss, Mr. A. E. Pickford, and Mr. W. R. Reader 
for help in obtaining the poplar twigs used as breeding material in this project. Thanks are due also to Mr. Rawley Frith for raising some of the hybrid seedlings, and to Dr. L. P. V. Johnson for valuable aid in effecting some of the crosses and in bringing the resulting hybrids through the most difficult seedling stage. To Dr. R. Newton, Director of the Division of Biology and Agriculture, National Research Council of Canada, appreciation is due for the facilities made available and constructive co-operation rendered during the more recent stages of this project. To Mr. C. G. Riley and Dr. J. E. Bier of the Division of Botany and Plant Pathology, Department of Agriculture, acknowledgment is due for observations and notes on the diseases of the parent and hybrid material.

\section{REFERENCES}

Albensky, A. V. and Delitsina, A. V. 1934. Experiment on hybridizing poplars in the laboratory. VNILAMI 2: 107-119.

Bier, J. E. 1939. Septoria canker of introduced and native hybrid poplars. Canadian Journal of Research C 17: 195-204.

Bogdanov, P. L. 1934. New method of vegetative propagation of poplars, Proc. Central Sci.-Inv. Inst. Forestry, 1:27-50.

Bogdanov, P. L. 1936. Poplars and their cultivation (Russian). Narkomles, Leningrad.

Cansdale, G. S. et al. 1938. The black poplars and their hybrids cultivated in Great Britain. Imperial Forestry Institute, Oxford.

Dobzhansky, T. 1937. Genetic nature of species differences. The American Naturalist 71: 404-420.

Heimburger, C. 1936. Report on poplar hybridization, 1936. The Forestry Chronicle 12: 285-290.

Heribert-Nilsson, N. 1918. Experimentelle Studien uber Variabilitat, Spaltung, Artbildung und Evolution in der Gattung Salix. Lunds Univ. Arsskr. N.F. 2. 14. (28): 1-145.

Hubbard, C. S. 1926. A review of the species of Populus introduced into South Africa. S. Afr. Journal of Science 23:340-365.

Moss, E. H. 1932. The vegetation of Alberta IV. The poplar association and related vegetation of central Alberta. Journal of Ecology 20:380-415.

Muntzing, A. 1936. The chromosomes of a giant Populus tremula. Hereditas 21:383-393.

Nilsson-Ehle, H. 1936. Ueber eine in der Natur gefundene Gigasform von Populus tremula. Hereditas 21:379-382.

Nilsson-Ehle, H. 1938. Framstallning av skogstrad med okat kromosomtal och okat virkesproduktion. Svensk Papperstidning 41:42-46.

Peace, T. R. 1939. The resistance of poplars to canker and other diseases. Imperial Forestry Institute Leaflet No. 1.

Peto, F. H. 1938. Cytology of poplar species and natural hybrids. Canadian Journal of Research C 16:445-455.

Rehder, A. 1927. Manual of cultivated trees and shrubs hardy in North America. New York.

Schreiner, E. J. 1939. The possibilities of the clone in forestry. Journal of Forestry 37:61-62.

Stout, A. B. and Schreiner, E. J. 1933. Results of a project in hybridizing poplars. Journal of Heredity 24:217-229. 
Stout, A. B. and Schreiner, E. J. 1934. Hybrids between the necklace cottonwood and the large-leaved aspen. Journal of the New York Botanic Garden 35: 140-143.

Tidestrom, I. 1911. Notes on Populus Plinius. American Midland Naturalist $2: 29-35$.

Wettstein, W. v. 1933 a. Die Kreuzungsmethode und die Beschreibung von F1 Bastarden bei Populus. Zeitschrift fur Zuchtung A. Pflanzenzuchtung 18: $597-626$.

Wettstein, W. v. 1933 b. Die Zuchtung von Populus II. Der Zuchter 5:280-281.

Wettstein, W. v. 1937 a. Die Vermehrung und Kultur der Pappel. Frankfurt a. M.

Wettstein, W. v. 1937 b. Individuelle Unterschiede bei Aspensamlingen Forstarchiv 13:149-151.

Wettstein, W. v. 1938. Transgression und Heterosis bei Populus-Kreuzungen. Forstwissenschaftliches Centralblatt 60:555-558. 